\title{
Energy Performance Evaluation of a Recycled Water Heat Pump System in Cool and Dry Climate Zone
}

\author{
Piljae Im, PhD
}

\author{
Xiaobing Liu, PhD
}

\begin{abstract}
This paper presents performance evaluation results for a recycled water heat pump (RWHP) system, which uses the recycled water from a municipal water system as a heat sink and heat source for heat pumps. The temperature of the recycled water, system heat flow, and efficiency were analyzed based on measured data from December 2014 through August 2015. The annual energy consumption of the RWHP system was compared with that of a baseline system - a conventional variable-air-volume system using a water-cooled chiller and a natural gas-fired boiler, both of which meet the minimum energy efficiencies allowed by ASHRAE 90.1-2013. The analysis results indicate that, on an annual basis, the RWHP system bas avoided 50\% of source energy consumption, reduced $\mathrm{CO}_{2}$ emissions by $41 \%$, and saved $34 \%$ in energy costs compared with the baseline system.
\end{abstract}

\section{INTRODUCTION}

In 2009, 26 projects were competitively selected and funded with American Recovery and Reinvestment Act (ARRA) grants to demonstrate innovative ground source heat pump (GSHP) technologies. Denver Museum of Nature and Science (DMNS) in Denver, Colorado, was one of the 26 demonstration project sites. The new facility is a five-story, 140,000-gross-square-foot addition to the museum. The innovation of the demonstrated GSHP technology at this site is that this system uses water from the city's underground municipal recycled (non-potable) water system as the heat sink and heat source for the heat pump in lieu of the borehole field used in conventional GSHP systems. This project is believed to be the first of its kind in the United States. The demonstrated technology, called recycled water heat pump (RWHP), has potential to be applied in other urban areas, given that there are existing RW distribution systems in many cities. For example, the existing RW system in Denver is over 70 miles long and is still expanding, and currently 171 water districts in 11 states in the United States have existing RW systems. Currently, the RW is mainly used for landscape irrigation and pond water-level management.

This case study was conducted based on the available measured performance data from December 2014 through August 2015, utility bills for the building in 2014 and 2015, construction drawings, maintenance records, personal communications, and construction costs. The annual energy consumption of the RWHP system was compared with that of a baseline scenario-a conventional variable-air-volume (VAV) system using a water-cooled chiller and a natural gas-fired boiler, both of which meet the minimum energy efficiencies allowed by ASHRAE 90.12013 (ASHRAE 2013). The comparison was made to determine energy savings, operating cost savings, and $\mathrm{CO}_{2}$ emission reductions achieved by the RWHP system. A cost analysis was also performed to evaluate the simple payback of the RWHP system. More detailed information for this case study is given by Im and Liu (2015).

Xiaobing Liu (liux2@ornl.gov) and Piljae Im are R\&D staff at Oak Ridge National Laboratory.

This manuscript has been coauthored by UT-Battelle, LLC under Contract No. DE-AC05-00OR22725 with the U.S. Department of Energy. The United States Government retains and the publisher, by accepting the article for publication, acknowledges that the United States Government retains a non-exclusive, paid-up, irrevocable, world-wide license to publish or reproduce the published form of this manuscript, or allow others to do so, for United States Government purposes. The Department of Energy will provide public access to these results of federally sponsored research in accordance with the DOE Public Access Plan (http://energy.gov/downloads/doe-public-access-plan). 


\section{BUILDING AND SYSTEM DESCRIPTION}

The host building is a new addition, the Education and Collection Facility building, to the existing DMNS building. This 140,000 $\mathrm{ft}^{2}$ building has five stories (including two stories underground). The RWHP system uses seven 30-ton modular water-to-water heat pumps (WWHPs). Each WWHP uses R-410A refrigerant, has two compressors, and can independently provide either hot water (HW) or chilled water (CHW) to the building. A master controller modulates the operation mode of each WWHP to satisfy the varying heating and cooling demands of the building. The RWHP system can provide HW and CHW simultaneously. As shown in Fig. 1, the RWHP system has five water loops: the RW loop, source water loop, CHW loop, HW loop, and precooling loop. Each loop has its own circulation pump and associated controls. Since RW may not always be available because of routine maintenance or other reasons, the RWHP system also has two steam heat exchangers (HXs) to provide supplemental heating, and a cooling tower that serves as a backup heat sink when RW is not available or not sufficient to keep the source water temperature within a desired range. The precooling loop provides cold water to the five air-handling units (AHUs) in the building (one for each floor) and serves as the heat source for a separate WWHP unit dedicated to domestic hot water (DHW) heating. Water in this loop is cooled by the source water loop and the WWHP for DHW. The supply cold water temperature is designed to be between 45 and $75^{\circ} \mathrm{F}$, with a maximum $10^{\circ} \mathrm{F}$ temperature rise in the return water. The heat rejected from the precooling loop goes to the source water loop and becomes a heat source for the modular WWHPs (for producing CHW and HW). Table 1 is a list of data points related to the RWHP system, which are indicated in Fig. 1.

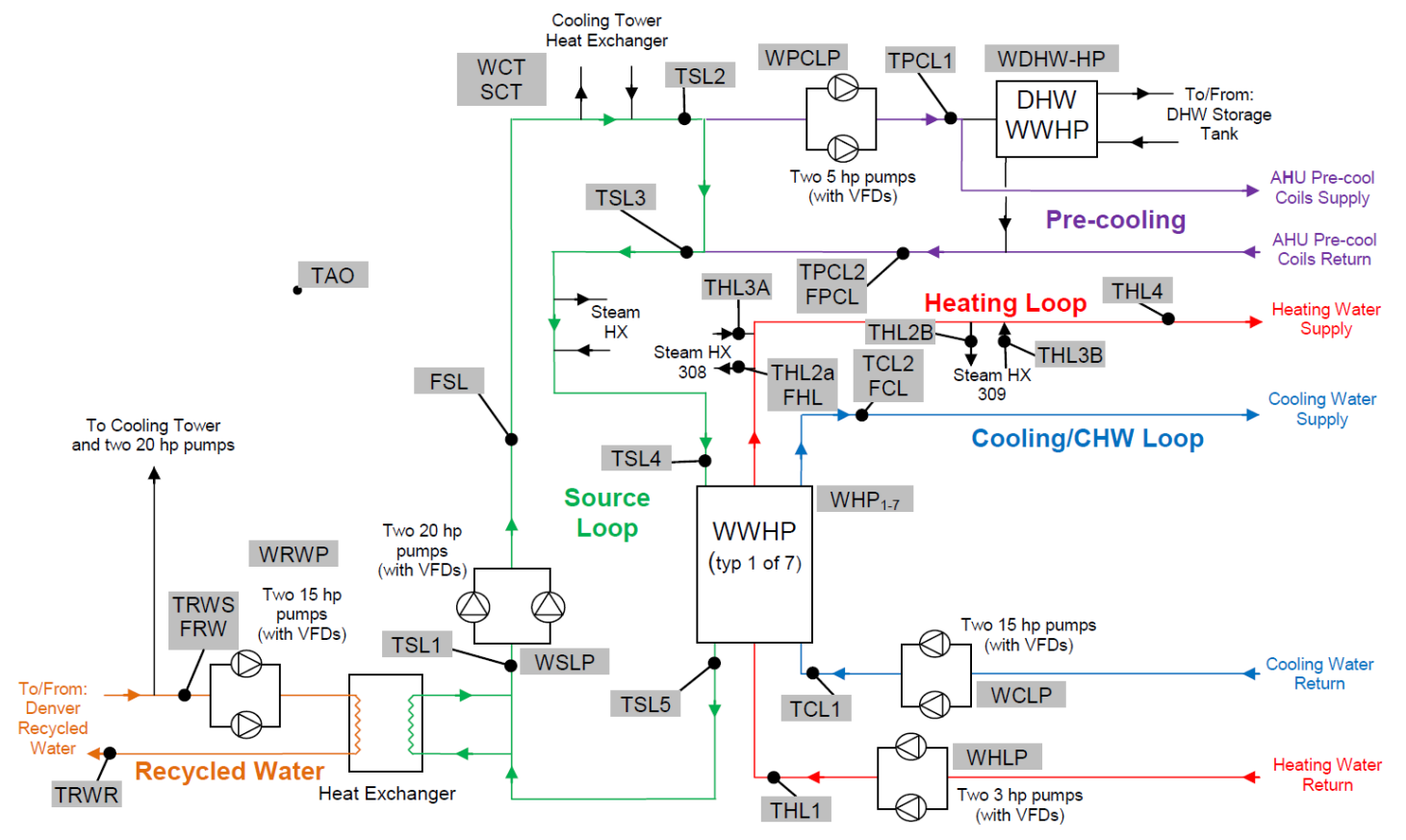

Fig. 1. A schematic of the recycled water heat pump system with monitored data points shown.

A new pipeline for the RW was constructed between the existing city RW pipeline and the target building. Two 8-inch PVC pipes (one for supply and the other for return) were installed side by side in a 48-inch-wide trench. The supply line was insulated with 2 inches of foam insulation to reduce heat transfer between the supply and return lines. Trench depth varied from 6 feet to 15 feet through the 3,300-foot-long pipeline (in each direction). Remote water sampling stations were required on the lines between the conduit and building entry points. Isolation valves and a meter were installed at the conduit connection. Other isolation valves were installed at points before the lines enter 
the building. RW is pumped through a plate frame HX (referred as "RW HX" hereinafter; shown in Fig. 1) by two 15hp redundant variable-speed pumps (referred as the "RW pump" hereinafter) to exchange heat with the source water.

Table 1. RWHP System Monitoring Data Points

\begin{tabular}{llll}
\hline Label & \multicolumn{1}{c}{ Description } & Label & \multicolumn{1}{c}{ Description } \\
\hline \hline TRWS & Recycled Water Supply Temperature & THL3b & HW Loop Temp after Steam HX 309 \\
TRWR & Recycled Water Return Temperature & FHL & HW Loop Flow \\
FRW & Recycled Water Flow & WHLP & HW Loop Pump Power \\
WRWP & Recycle Water Pumps Power & TCL1 & CHW Loop Temperature to WWHPs \\
TSL1 & Source Loop after RW HX Temperature & TCL2 & CHW Loop Temperature from WWHPs \\
TSL2 & Source Loop after Cooling Tower & FCL & CHW Loop Flow \\
& Temperature & WCLP & CHW Loop Pump Power \\
TSL3 & Source Loop after Pre-cool Loop Temperature & WDHW-HP & DHW WWHP Power \\
TSL4 & Source Loop after Steam HX Temperature & TPCL1 & Pre-Cooling Loop Temperature prior to \\
TSL5 & Source Loop after WWHP Temperature & & DHW WWHP \\
& & TPCL2 & Pre-Cooling Loop Temperature after \\
FSL & Source Loop Flow & & DHW WWHP \\
& & FPCL & Flow pre-Cooling Loop \\
WSLP & Source Loop Pump Power & WPCLP & Pre-Cooling Loop Pump Power \\
WHP1-7 & Heat Pump Power (WWHPs 1 through 7) & WCT & Cooling Tower Power \\
THL1 & HW Loop Temperature to WWHPs & SDHWHP & DHW Heat Pump Status \\
THL2a & HW Loop Temp before Steam HX 308 & TDHWHPS & DHW Heat Pump Supply Temp \\
THL2b & HW Loop Temp before Steam HX 309 & TAO & Ambient Temperature \\
THL3a & HW Loop Temp after Steam HX 308 &
\end{tabular}

The control sequence for the RW pump is different in heating and cooling seasons. During cooling season, the RW pump is turned on when the leaving water temperature from the RW HX (TSL1 in Fig. 1 ) is above $55^{\circ} \mathrm{F}$ and the leaving water temperature from the modular WWHP (TSL5 in Fig. 1) is at least $2^{\circ} \mathrm{F}$ higher than the RW supply temperature (TRWS in Fig. 1). During heating season, the RW pump is turned on when TSL1 is below $55^{\circ} \mathrm{F}$ and the TSL5 is at least $2^{\circ} \mathrm{F}$ lower than TRWS. When it is turned on, the speed of the RW pump is modulated to maintain the temperature differential of the RW at $10^{\circ} \mathrm{F}$ across the RW HX.

\section{RESULTS}

\section{Recycled Water Temperature}

Hourly RW temperatures during the period from January through August 2015 are plotted in Fig. 2 along with the hourly outdoor air (OA) temperatures (OATs). As shown in this figure, the RW temperature was relatively stable throughout the monitored period, whereas the OAT fluctuated to a much larger degree during the same period.

Although the monthly average RW and OA dry bulb temperatures during the cooling season (June through August) were close to each other, the OAT fluctuated in a much larger range during each month. The maximum OA dry bulb temperature (indicated as "OAT") was $94.5^{\circ} \mathrm{F}$ during the 8 month period, whereas the maximum RW temperature was $83.2^{\circ} \mathrm{F}$ during the same period. On the other hand, the monthly average OA wet bulb temperature at Denver is always below $60^{\circ} \mathrm{F}$ during the same period, which indicates that a wet cooling tower would be very effective to cool the source water in this climate. The minimum RW temperature $\left(38.8^{\circ} \mathrm{F}\right)$ was much higher than the minimum OAT $\left(7.6^{\circ} \mathrm{F}\right)$. A closer look at the OA and RW temperatures from July 15 through 17 reveals that whereas the RW supply temperature (indicated as "TRWS") was higher than the OAT in the nighttime, it was lower than the OAT in the daytime when cooling demands were high (see the upper chart in Fig. 3). Since a lower heat sink temperature will lead to higher cooling efficiency in a heat pump, using RW as a heat sink during the daytime can result in lower cooling energy consumption than using OA. Furthermore, as shown in the lower chart of Fig. 3, TRWS was higher than OAT all the time during typical days in winter (January 20-22), which indicates RW is a better heat source than OA. 


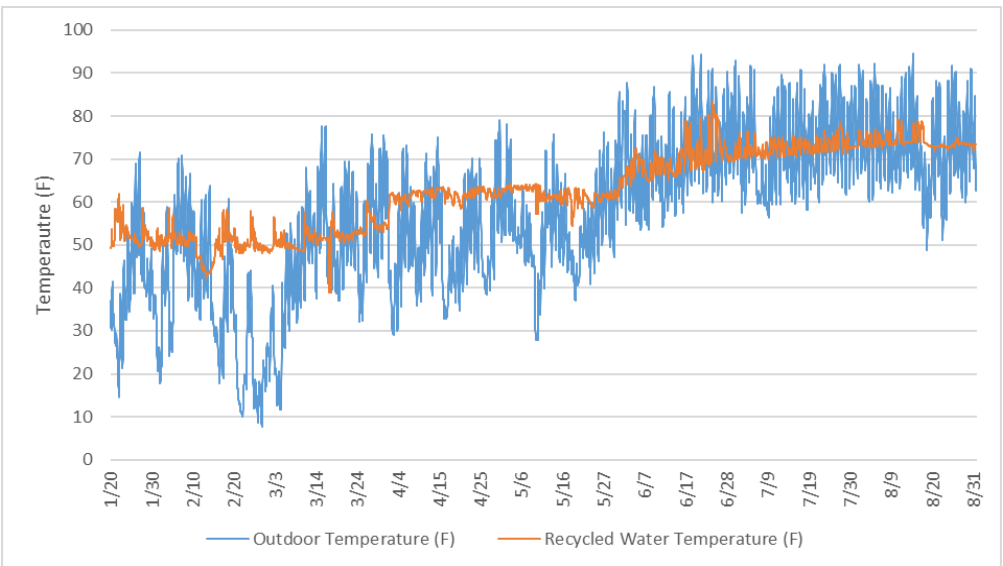

Fig. 2. Hourly OA temperature vs. RW temperature.

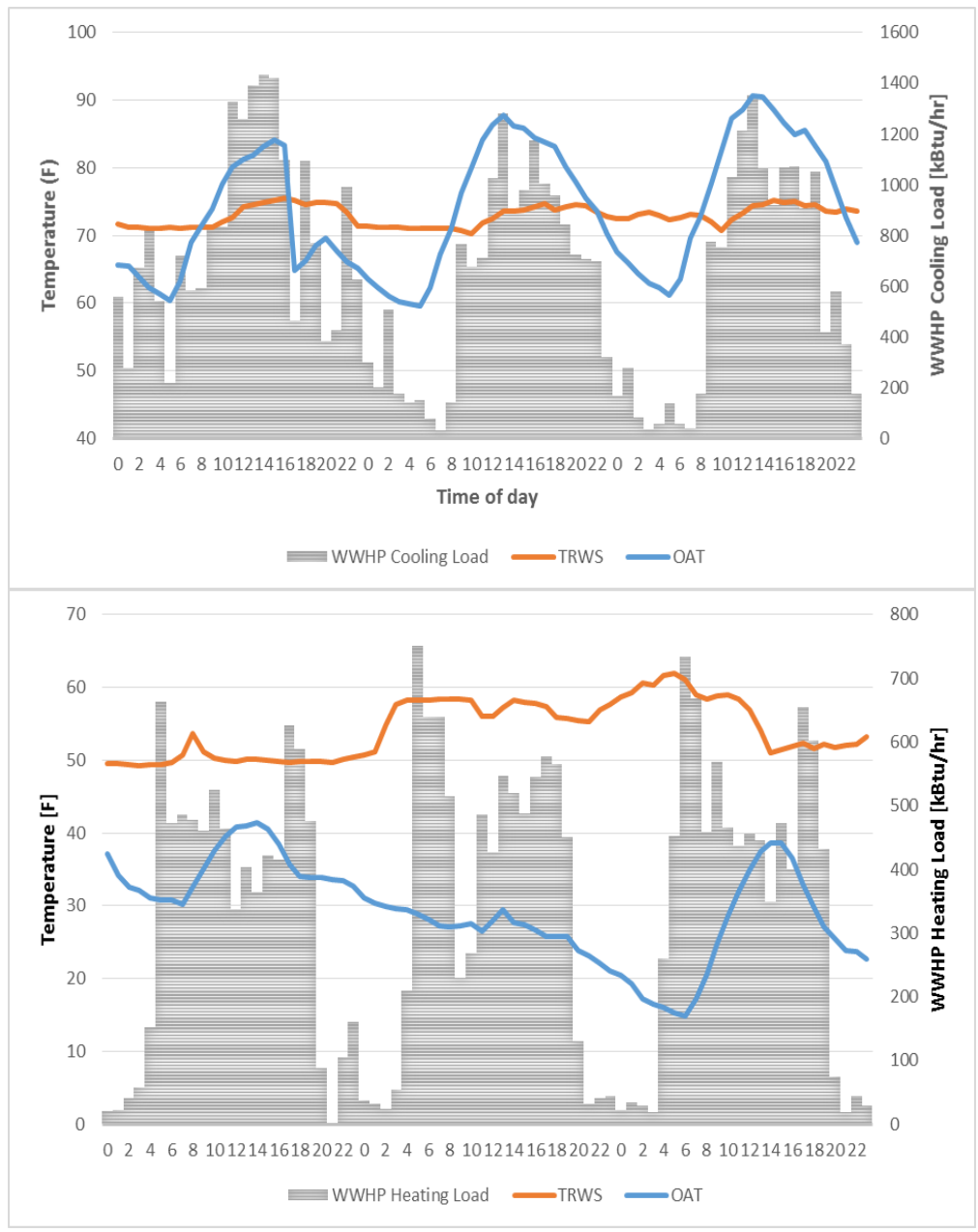

Fig. 3. Outdoor air (OA) dry bulb temperature, recycled water (RW) temperature, and water-to-water heat pump (WWHP) loads during typical days in the cooling season (top) and heating season (bottom). 


\section{Heat Flow Analysis}

Heat flows from the various heat sinks and sources in the source water loop were analyzed to quantify their contributions. Figure 4 shows the monthly heat flows, which are grouped into two categories: heat extracted from the various heat sources (with positive values) and heat rejected to various heat sinks (with negative values). As can be seen in this figure, the heat flows demonstrated two different patterns. During heating season (i.e., December 2014 through May 2015), most heat ( $70 \%)$ was extracted from the precooling loop and the rest was extracted from the RW and the steam HX. While most of these additions were used by the WWHPs to generate HW, a fair amount of heat was rejected to the cooling tower and the RW. The purpose of the heat rejection was to make the source water cool enough to precool the air in the AHUs. In contrast, during cooling season (June through August, 2015), roughly an equal amount of heat was rejected by the WWHPs (i.e., the condensing heat from the cooling operation of the WWHPs) and the precooling loop. Only a small amount of heat was extracted from the RW. Most of the heat $(\sim 60-$ $70 \%$ ) added to the source water was rejected to the ambient air by the wet cooling tower and about $20-30 \%$ of the heat was rejected to the RW. The rest was used by the WWHPs when they ran in heating mode.

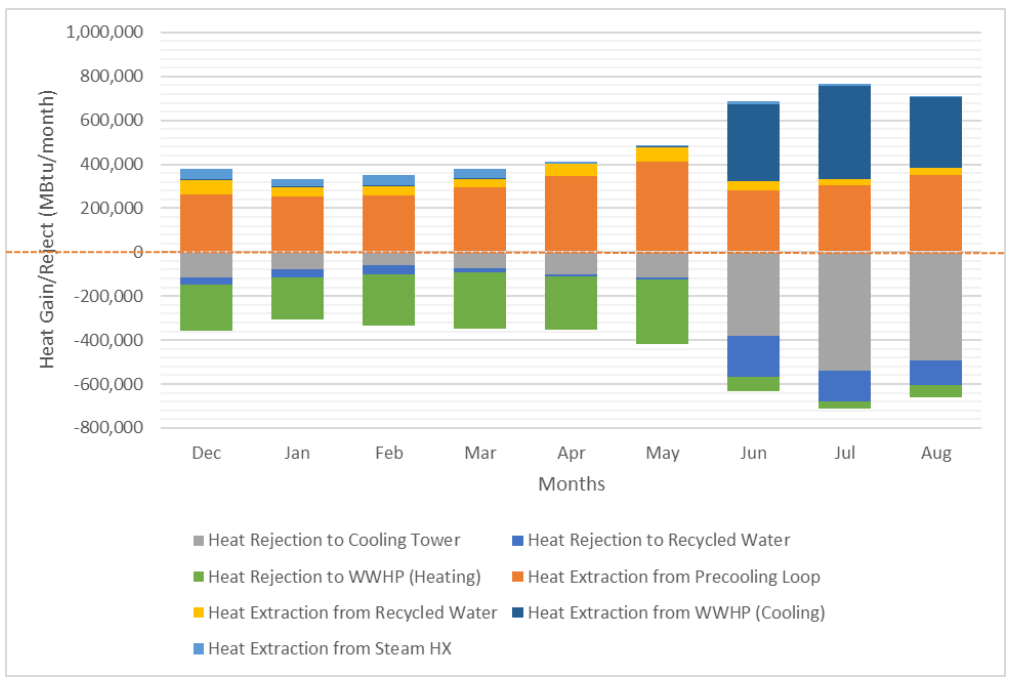

Fig. 4. Monthly heat flows in the source water loop.

\section{System COP Analysis}

Because the RWHP system provided simultaneous cooling and heating, the "effective COP," which accounts for both heating and cooling operation, was calculated to evaluate the performance of the WWHPs and of the entire RWHP system. Figure 5 presents the effective COP for the WWHPs and the RWHP system for each $10^{\circ} \mathrm{F}$ bin of the OAT. It shows, in general, the effective COP increases with the increase in OAT. The effective COP of the WWHPs was about 5.6-6.0 when the OAT is higher than $70^{\circ} \mathrm{F}$ (i.e., when most modules of the WWHPs ran in cooling mode). This is consistent with the manufacturer's catalog data, which indicates that the cooling COP of the WWHP ranges within 5.9-6.2 under similar operating conditions (i.e., $75^{\circ} \mathrm{F}$ water entering condenser and $45^{\circ} \mathrm{F}$ water leaving evaporator). The effective COP of the entire RWHP system-which accounts for the supplemental heat input from the steam HX in the source loop as well as the power consumptions of the cooling tower, the RW pump, and the source loop pumps-rose from 2.6 to 4.4 with the increase in OAT, which is coincidental with the increased simultaneous heating and cooling operation. 


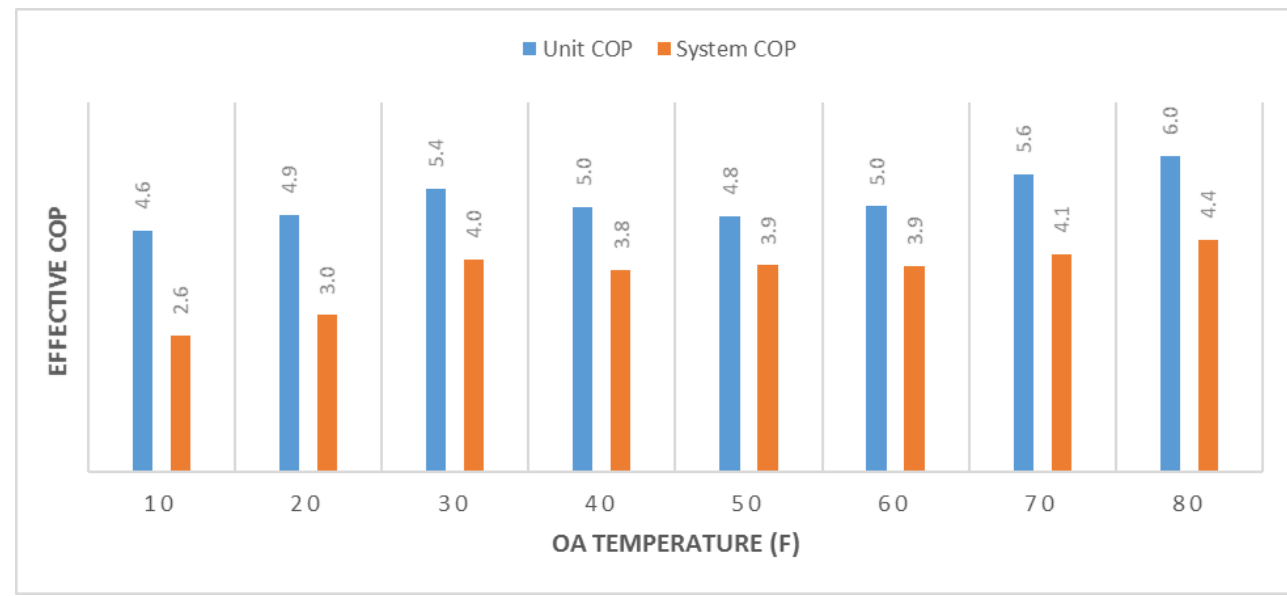

Fig. 5. Effective COPs of the WWHPs and the RWHP system versus outdoor air (OA) temperatures.

\section{Energy and Cost Savings Potential}

To estimate the energy saving potential of the RWHP system, the energy consumption of a conventional VAV system using a water-cooled chiller and a natural gas boiler was calculated as a baseline for providing the same heating and cooling outputs as the RWHP system. The energy efficiency of the chiller and the boiler used in the baseline were the minimum values allowed by ASHRAE 90.1-2013. The following are the major assumptions for calculating the baseline energy consumption and energy savings:

- It is assumed that there is no difference in the power consumption of the source loop pumps, CHW loop pumps, and HW loop pumps between the baseline and the RWHP systems.

- The water-cooled chiller has a nominal cooling COP of 5.54. A generic performance curve for watercooled chillers was adopted from the DOE-2 program (Hirsch et al. 2016) and used to calculate the chiller power consumption for providing the same hourly cooling output as the RWHP system (including outputs from both the precooling and CHW loops).

- The natural gas-fired boiler has a thermal efficiency of $80 \%$ and provides the same hourly heating outputs as both the WWHPs and the steam HXs in the HW loop.

- The cooling tower power consumption of the baseline system is calculated based on the average heat rejection efficiency of a typical cooling tower, which depends on the average wet-bulb temperature in each month.

- Average utility rates obtained from 2014 and 2015 utility bills were used for energy cost calculations. The average electricity rate is $\$ 0.076 / \mathrm{kWh}$ and the natural gas rate is $\$ 4.84 / \mathrm{MMBtu}$.

The source energy consumption and carbon emissions of the two systems were calculated based on the measured consumption of electricity and natural gas by the RWHP system and the simulation-predicted electricity and natural gas consumption of the baseline system. The site-source energy conversion factors and the emission factors of electricity and natural gas suggested by Deru and Tocellini (2007) were used in the calculations. Table 2 shows the annual performance comparison between the baseline and the RWHP systems. The analysis shows that the total annual energy cost savings would be $\$ 16,295$ (34\% savings), and $\mathrm{CO}_{2}$ emission reductions associated with the energy savings would be approximately $41 \%$.

For the 8 months encompassed in this study, the RWHP system saved 2,507 MMBtu of source energy (a 47\% savings) and $\$ 11,386$ in energy costs (a 37\% reduction) compared with the baseline system. Considering the costs associated with using RW ( $\$ 0.078$ per 1,000 gallons of RW passing though the heat exchanger) and additional cooling tower make-up water for the baseline system, which are about $\$ 807$ and $\$ 500$, respectively, the operating cost savings 
of the RWHP system is $\$ 10,157$ (33\% savings).

Because the available measured data cover only 8 months, the energy use of the two systems during the rest of a 1-year period (September through December, 2014) was estimated to assess the annual energy savings potential of the RWHP system. (The results are listed in Table 2.) The estimation procedure included two steps:

- Derive correlations between the monthly energy use of each major component of the two systems and the monthly average OAT based on available data from January through August in 2015

- Estimate the energy use of the two systems with the derived correlations and the historical OAT data from September through December 2014.

Table 2. Comparison of Annual Performance between Baseline and RWHP Systems

\begin{tabular}{|c|c|c|c|c|}
\hline & \multicolumn{2}{|c|}{ Baseline system } & \multicolumn{2}{|c|}{ RWHP system } \\
\hline & Electricity & Natural gas & Electricity & Natural gas \\
\hline Annual HVAC related site energy & $\begin{array}{r}331,509 \\
\mathrm{kWh}\end{array}$ & 4,742 MMBtu & $334,419 \mathrm{kWh}$ & 969 MMBtu \\
\hline $\begin{array}{l}\text { Annual HVAC related source energy } \\
\text { (MMBtu) }\end{array}$ & \multicolumn{2}{|c|}{8,191} & \multicolumn{2}{|c|}{4,098} \\
\hline Source energy savings (MMBtu) & \multicolumn{2}{|c|}{-} & \multicolumn{2}{|c|}{4,094} \\
\hline$\%$ of source energy savings & \multicolumn{2}{|c|}{-} & \multicolumn{2}{|c|}{$50.0 \%$} \\
\hline Energy cost by fuel type (\$) & $\$ 25,195$ & $\$ 22,953$ & $\$ 25,416$ & $\$ 4,692$ \\
\hline Total energy cost $(\$)$ & \multicolumn{2}{|c|}{$\$ 48,148$} & \multicolumn{2}{|c|}{$\$ 30,108$} \\
\hline Recycled water use $(\$)$ & \multicolumn{2}{|c|}{-} & \multicolumn{2}{|c|}{$\$ 2,398$} \\
\hline Additional make-up water $(\$)$ & \multicolumn{2}{|c|}{$\$ 654$} & & \\
\hline Annual cost savings $(\$)$ & \multicolumn{2}{|c|}{-} & \multicolumn{2}{|c|}{$\$ 16,295$} \\
\hline$\%$ of cost savings & \multicolumn{2}{|c|}{-} & \multicolumn{2}{|c|}{$33.8 \%$} \\
\hline $\mathrm{CO}_{2}$ emissions (lb) by fuel type & 543,675 & 578,565 & 548,447 & 118,278 \\
\hline Total $\mathrm{CO}_{2}$ emissions $(\mathrm{lb})$ & \multicolumn{2}{|c|}{$1,122,239$} & \multicolumn{2}{|c|}{666,725} \\
\hline $\mathrm{CO}_{2}$ emission reductions $(\mathrm{lb})$ & \multicolumn{2}{|c|}{-} & \multicolumn{2}{|c|}{455,515} \\
\hline$\%$ of $\mathrm{CO}_{2}$ emission reductions & \multicolumn{2}{|c|}{-} & \multicolumn{2}{|c|}{$40.6 \%$} \\
\hline
\end{tabular}

The normalized cost of the RWHP system (including the AHUs and the ductwork system inside the building) is $\$ 25,210 /$ ton of installed cooling capacity, or $\$ 37.8 / \mathrm{ft}^{2}$ of building floor space. With the achieved annual energy cost savings, the simple payback for this system is about 58 years. This long payback period is due to the high cost of constructing a 3,300 ft long two-way pipeline to access the RW. The pipeline cost is $\$ 1.1$ million, which accounts for about $20 \%$ of the total system cost. If the length of the pipeline were $1,000 \mathrm{ft}$, the simple payback would be reduced to 11 years.

\section{CONCLUSION}

\section{Energy Performance and Cost-Effectiveness}

- The measured RW temperatures from the demonstration site during the encompassed period show that RW was more favorable than OA for effective operation of the WWHPs. The maximum OAT was about $94.5^{\circ} \mathrm{F}$ during the cooling season, whereas the maximum RW temperature was about $83.2^{\circ} \mathrm{F}$. The lowest RW temperature was about $38.8^{\circ} \mathrm{F}$ during the heating season, whereas the lowest $\mathrm{OAT}$ was below $10^{\circ} \mathrm{F}$.

- Effective COPs of the WWHPs and of the entire RWHP system, which account for the simultaneous cooling and heating, were calculated based on the measured data. The effective COP of the WWHPs ranged from 4.6 to 6.0 , whereas the effective COPs of the RWHP system ranged from 2.6 to 4.4 during the 8 month 
investigative period of this study. The system COP increased with the increase in OAT, which is in part a result of the increased simultaneous heating and cooling demands.

- The demonstrated RWHP system saved 4,094 MMBtu of source energy (a 50.0\% savings) and \$16,295 in energy costs (a 33.8\% savings) annually, compared with a conventional VAV system using a water-cooled chiller and a natural gas-fired boiler, both of which meet the minimum energy efficiencies allowed by ASHRAE 90.1-2013. The energy savings also resulted in a 41\% reduction in $\mathrm{CO}_{2}$ emissions.

- The simple payback period of this system is about 58 years. However, if the length of the pipeline for accessing the RW were shortened from $3,300 \mathrm{ft}$ to $1,000 \mathrm{ft}$, the simple payback would be reduced to 11 years.

\section{Lessons Learned}

- The run-around heat recovery through the precooling loop was very effective and significantly reduced the demand for external heat sources (e.g., the RW and the steam HX). The wet cooling tower rejected more heat than the RW because of the relatively dry air in the Denver area.

- Contributions of the steam HXs were very small, and it is likely that the RWHP system could work well without the boiler and the steam HXs, or with just a smaller water heater as a backup. Such a configuration would reduce the complexity and the associated cost of the RWHP system.

- The RWHP system would be economically more competitive if the RW were closer to the building.

\section{ACKNOWLEDGMENTS}

The authors thank the Emerging Technologies Program of the Buildings Technology Office at the U.S. Department of Energy for supporting this research project.

\section{REFERENCES}

ASHRAE 2013. ANSI/ASHRAE/IES Standard 90.1-2013, Energy Standard for Buildings Except Low-Rise Residential Buildings, American Society of Heating, Refrigerating and Air-Conditioning Engineers, Atlanta.

Deru, M., and P. Tocellini. 2007. Source Energy and Emission Factors for Energy Use in Buildings, Technical Report, NREL/TP-550-38617, National Renewable Energy Laboratory, Golden, Colorado.

Hirsch J. et al. 2016. eQUEST program. Available at www.doe2.com

Im, P. and X. Liu. 2015. Case Study for the ARRA-funded GSHP Demonstration at Denver Museum of Natural and Science, ORNL/TM-2015/473, Oak Ridge National Laboratory, Oak Ridge, Tennessee. 